\title{
Molecular Relationships of Fungi Within the Fusarium redolens-F. hostae Clade
}

\author{
Robert P. Baayen, Kerry O’Donnell, Suzanne Breeuwsma, David M. Geiser, and Cees Waalwijk
}

First author: Mycology Section, Plant Protection Service, P.O. Box 9102, 6700 HC Wageningen, the Netherlands; second author: Microbial Properties Research Unit, National Center for Agricultural Utilization Research, United States Department of Agriculture-Agricultural Research Service, 1815 North University Street, Peoria, IL; third author: Bulb Research Center, P.O. Box 85, 2160 AB Lisse, the Netherlands: fourth author: Fusarium Research Center, Department of Plant Pathology, The Pennsylvania State University, University Park; and fifth author: Plant Research International, Wageningen University and Research, P.O. Box 16, 6700 AA Wageningen, the Netherlands. Accepted for publication 25 June 2001.

\begin{abstract}
Baayen, R. P., O'Donnell, K., Breeuwsma, S., Geiser, D. M., and Waalwijk, C. 2001. Molecular relationships of fungi within the Fusarium redolens-F. hostae clade. Phytopathology 91:1037-1044.

The evolutionary relationships of fungi in the Fusarium redolens $-F$. hostae clade were investigated by constructing nuclear and mitochondrial gene genealogies for 37 isolates representing the known genetic and pathogenic diversity of this lineage, together with 15 isolates from putative sister groups that include the Gibberella fujikuroi and $F$. oxysporum species complexes and related species. Included in the analyses were 29 isolates of F. redolens from Asparagus, Convallaria, Dianthus, Fritillaria, Hebe, Helleborus, Hordeum, Linum, Pisum, Pseudotsuga, and Zea spp., and from soil. Isolates of $F$. hostae analyzed included two reference isolates from Hosta spp. and six isolates from Hyacinthus spp. that originally were classified as $F$. oxysporum $\mathrm{f}$. sp. hyacinthi. DNA sequences

from a portion of the nuclear translation elongation factor $1 \alpha(\mathrm{EF}-1 \alpha)$ gene and the mitochondrial small subunit (mtSSU) ribosomal RNA (rRNA) were analyzed individually and as a combined data set based on results of the nonparametric Wilcoxon signed ranks Templeton combinability test. Maximum parsimony analysis of the combined data set identified the $F$. redolens $-F$. hostae clade as a sister group to a phylogenetically diverse clade in which the G. fujikuroi species complex formed the most basal lineage. Also included in this latter clade were two unnamed Fusarium spp. that are morphologically similar to $F$. oxysporum and putative sister taxa comprising the $F$. oxysporum complex and a $F$. nisikadoi-F. miscanthi clade. Phylogenetic diversity in $F$. redolens was small; all isolates were represented by only three EF-1 $\alpha$ and two mtSSU rDNA haplotypes. Both the isolates of $F$. redolens $\mathrm{f}$. sp. asparagi and those of $F$. redolens f. sp. dianthi were nearly evenly distributed in the combined molecular phylogeny between the two major subclades within F. redolens.
\end{abstract}

The soilborne fungus Fusarium oxysporum Schlechtend.:Fr. is one of the economically most important plant pathogenic fungi worldwide. More than 150 host-specific formae speciales have been described in $F$. oxysporum, many of them subdivided into distinct pathogenic races. F. oxysporum was placed in the Fusarium section Elegans by Wollenweber (42), together with six other taxa (F. tracheiphilum, F. vasinfectum, F. vasinfectum var. inodoratum, $F$. lycopersici, $F$. niveum, and $F$. redolens) that have been considered synonymous with $F$. oxysporum since Snyder and Hansen (35). In the past decade, molecular studies have shown that these morphologically highly similar fungi have multiple phylogenetic origins $(4,30)$. The fungi involved are currently referred to as the F. oxysporum complex, which consists of three well-supported main clades, each in turn consisting of numerous phylogenetic lineages, most of which do not coincide with known formae speciales $(4,30)$.

The position of $F$. redolens Wollenweb. as a member of the $F$. oxysporum complex has been disputed for many years. Wollenweber's morphological differentiation of $F$. redolens and $F$. oxysporum (42) is problematic due to the presence of intermediate forms (3), such that many authors have treated both species as conspecific $(24,35)$, or at best have recognized $F$. redolens as a variety of $F$. oxysporum $(10,16)$ or even $F$. solani $(7)$. Studies employing the ribosomal DNA (rDNA) internal transcribed spacer (ITS) region and gene sequence analyses have since confirmed

Corresponding author: R. P. Baayen; E-mail address: r.p.baayen@pd.agro.nl

Publication no. P-2001-0905-01R

This article is in the public domain and not copyrightable. It may be freely reprinted with customary crediting of the source. The American Phytopathological Society, 2001. that $F$. redolens is distinct from $F$. oxysporum $(29,38,39)$. Gene genealogies indicate that $F$. redolens is not even the sister group of the $F$. oxysporum complex $(4,11,29)$, challenging the phylogenetic validity of Fusarium section Elegans $(38,39)$. Instead, a sister group relationship has been reported of the $F$. oxysporum complex and a $F$. miscanthi-F. nisikadoi clade, two closely related putatively Asian species with the potential to produce pyriform conidia (11).

Like the $F$. oxysporum complex, $F$. redolens harbors isolates causing a wide range of diseases including wilts, seedling damping-off, and cortical rot; several of these show host specificity $(10,14,15)$. The original description was based on an isolate from Pisum sativum that was identified as a vascular parasite and the cause of wilt and foot disease (42), later followed by isolates from rotten pea seeds (43). Booth (10) reported that $F$. redolens occurs in association with $F$. oxysporum $\mathrm{f}$. sp. pisi in a wilt of broad bean and of pea, and that each of these pathogens can cause wilting of pea separately, producing symptoms which are indistinguishable from one another. Gerlach and Pag (15) reported on a form from Dianthus spp., F. redolens f. sp. dianthi. This form colonizes xylem vessels and causes wilt symptoms that are indistinguishable from those induced by $F$. oxysporum f. sp. dianthi (3). F. redolens f. sp. dianthi was later shown to harbor four vegetative compatibility groups (VCGs), each of which represents a distinct race $(1,6,21)$. Additional associations between pathogenic forms of $F$. redolens and $F$. oxysporum have been reported. Thus, root and spear rot of asparagus can be caused by $F$. redolens f. sp. asparagi and by $F$. oxysporum f. sp. asparagi; both taxa cause cortical rot symptoms that are indistinguishable from one another, while the xylem is unaffected $(5,8)$. Oil palm is susceptible to $F$. oxysporum f. sp. elaeidis as well as $F$. redolens (17). In addition, wilt and root 
rot of spinach can be caused by $F$. redolens f. sp. spinaciae and $F$. oxysporum f. sp. spinaciae $(20,36)$.

$F$. hostae, a species described from Hosta plants suffering root and crown rot in nurseries in South Carolina, was recently identified as a sister of $F$. redolens by Geiser et al. (13). This species is similar to $F$. redolens morphologically in that it produces similar asexual spores, has similar gross colony characteristics, and often produces a distinctive odor. However, $F$. hostae differs from $F$. redolens in that it occasionally produces simple polyphialides and grows more slowly on potato-dextrose agar (PDA). Also, a teleomorph has been described for $F$. hostae (Gibberella hostae), whereas sexual reproduction is unknown for $F$. redolens. With no more than a single host, no data on host specificity in $F$. hostae are available.

Although the phylogenetic relationships within the $F$. oxysporum complex and the F. nisikadoi-F. miscanthi clade have been studied in detail in the past years, little attention has been paid so far to the phylogenetic relationships and pathogenic diversity in the $F$. redolens $-F$. hostae clade. A major reason for this lack of data is the difficult access to reliable isolates: $F$. redolens is a rare species that is often mistaken for $F$. oxysporum, and $F$. hostae has been described only in 2001 (13). The authors have accumulated as wide a collection as possible of $F$. redolens and $F$. hostae, representing the known genetic and pathogenic diversity in these two species, to fill this gap. The aim of this study was to examine the evolutionary diversity within the $F$. redolens $-F$. hostae clade, and to test whether host specialization in these fungi can be related to evolutionary origin. This was done by constructing nuclear and mitochondrial gene genealogies, using isolates of putative sister groups (the $F$. oxysporum complex and related species, and the Gibberella fujikuroi species complex) as a reference, and $F$. beomiforme as outgroup species.

\section{MATERIALS AND METHODS}

Fungal isolates. This study comprises all isolates of $F$. redolens in the collections of the first and second authors, covering nearly all isolates currently available of this rare species. We included isolates of $F$. redolens $\mathrm{f}$. sp. asparagi (5), isolates of $F$. redolens $\mathrm{f}$. sp. dianthi (6) belonging to VCG 0001, 0002, 0003, and 0004, as well as a putatively nonpathogenic VCG from Dianthus sp. (1), and isolates from nine additional host species (Table 1). Pathogenicity of isolates was not tested; therefore, isolates not belonging to F. redolens $\mathrm{f}$. sp. asparagi and f. sp. dianthi may or may not be pathogenic to the host species from which they were isolated, unless otherwise specified. Six isolates of $F$. oxysporum f. sp. hyacinthi from hyacinth and suspected to belong to $F$. redolens were also included. The recently published species $F$. hostae was represented by reference isolates of the two genotypes of this species (13). Isolates of the F. oxysporum complex and G. fujikuroi complex included representatives of the three major clades within each of these large species complexes $(4,11,29,30)$ together with phylogenetically related Fusarium spp. (Table 1). Isolates examined in this study have been deposited in the Agricultural Research Service Culture Collection (National Center for Agricultural Utilization Research, Peoria, IL), abbreviated as NRRL after its former name Northern Regional Research Laboratory, where they are stored cryogenically at $-175^{\circ} \mathrm{C}$.

TABLE 1. Isolates of Fusarium redolens, F. hostae, and related species included in this study

\begin{tabular}{|c|c|c|c|c|c|}
\hline Host, substrate & Forma specialis (race) $)^{\mathrm{a}}$ & $\mathrm{VCG}^{\mathrm{b}}$ & Origin & $\mathrm{NRRL}^{\mathrm{c}}$ & Original code ${ }^{\mathrm{d}}$ \\
\hline \multicolumn{6}{|l|}{ Fusarium beomiforme } \\
\hline Soil & $\ldots$ & $\ldots$ & New Caledonia & 25174 & BBA 65829 \\
\hline \multicolumn{6}{|l|}{ Fusarium hostae } \\
\hline Hosta $\mathrm{sp}$ & $\ldots$ & $\ldots$ & United States & 29889 & FRC O-2074 \\
\hline Hosta sp. & $\ldots$ & $\ldots$ & United States & 29891 & FRC O-2083 \\
\hline Hyacinthus sp. & $\ldots$ & $\ldots$ & The Netherlands & 29642 & LBO Hy1 \\
\hline Hyacinthus sp. & $\ldots$ & $\ldots$ & The Netherlands & 29643 & LBO Hy3 \\
\hline Hyacinthus sp. & $\ldots$ & $\ldots$ & The Netherlands & 29644 & LBO Hy4 \\
\hline Hyacinthus sp. & $\ldots$ & $\ldots$ & The Netherlands & 29645 & LBO Hy5 \\
\hline Hyacinthus sp. & $\ldots$ & $\ldots$ & The Netherlands & 29646 & LBO Hy6 \\
\hline Hyacinthus sp. & $\ldots$ & $\ldots$ & The Netherlands & 29647 & LBO Hy7 \\
\hline \multicolumn{6}{|l|}{ Fusarium miscanthi } \\
\hline Miscanthus sinensis & $\ldots$ & $\ldots$ & Denmark & 26231 & CBS 578.97 \\
\hline Miscanthus sinensis & $\ldots$ & $\ldots$ & Denmark & 26239 & S-1296-59 \\
\hline \multicolumn{6}{|l|}{ Fusarium nisikadoi } \\
\hline Phyllostachys nigra & $\ldots$ & $\ldots$ & Japan & 25179 & MAFF 237509 \\
\hline Phyllostachys nigra & $\ldots$ & $\ldots$ & Japan & 25183 & MAFF 237510 \\
\hline \multicolumn{6}{|l|}{ Fusarium oxysporum } \\
\hline Asparagus officinalis & f. sp. asparagi & 1001 & United States & $28973^{\mathrm{e}}$ & FGSC 6608 \\
\hline Cucumis melo & f. sp. melonis & 0136 & United States & $26406^{e}$ & $\mathrm{~K}-419$ \\
\hline Dianthus caryophyllus & f. sp. dianthi (1) & 0022 & Italy & $26964^{f}$ & F100 \\
\hline Linum usitatissimum & f. sp. lini & 044- & The Netherlands & $28928^{f}$ & N1 \\
\hline \multirow[t]{2}{*}{ Musa sp. } & f. sp. cubense & 0120 & Australia & $25603^{g}$ & $\mathrm{~A} 2$ \\
\hline & & & & & inued on next po \\
\hline
\end{tabular}

a ... Indicates none described.

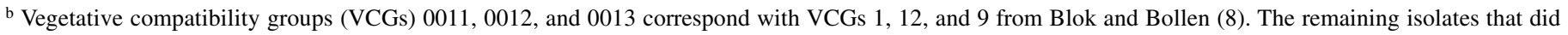
not react with reference tester strains from these VCGs, nor with each other, were placed in VCG 001-.

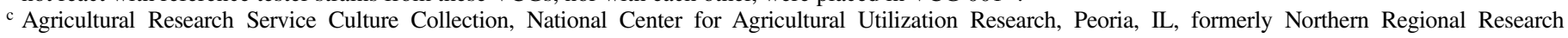
Laboratory.

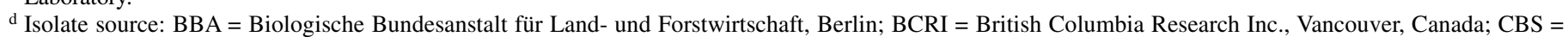
Centraalbureau voor Schimmelcultures, Utrecht, The Netherlands; CWB = W. J. Blok, Wageningen University, Wageningen, The Netherlands; DSM = Deutsche Sammlung von Mikroorganismen und Zellkulturen, Braunschweig, Germany; FGSC = Fungal Genetics Stock Center, Kansas; FRC = Fusarium Research Center, State College, PA; IMI = CABI Bioscience (formerly International Mycological Institute), Egham, U.K.; IPO = Plant Research International (formerly Instituut voor Planteziektenkundig Onderzoek), Wageningen, The Netherlands; LBO = Bulb Research Centre, Lisse, The Netherlands; MAFF = Ministry of Agriculture, Forestry, and Fisheries, NIAR, Tsukuba, Japan; PD = Plantenziektenkundige Dienst, Wageningen, The Netherlands.

e Member of $F$. oxysporum complex clade 3.

${ }^{\mathrm{f}}$ Member of $F$. oxysporum complex clade 2.

g Member of F. oxysporum complex clade 1.

h According to Baayen et al. (6).

i According to Aloi and Baayen (1) these two isolates belong the same VCG. 
DNA amplification and sequencing. Genomic DNA was prepared as described previously (28). Polymerase chain reaction amplification and sequencing of a portion of the mitochondrial small subunit (mtSSU) rDNA was performed by using reagents and primers described in White et al. (41) and O'Donnell and Cigelnik (28). A partial fragment of the elongation factor $1 \alpha$ (EF$1 \alpha)$ gene was amplified with primers EF-1 and EF-2, which prime within conserved exons (30). One forward (EF-11) and two reverse internal sequencing primers (EF-21 and EF-22) (30) were used with the fluorescent-labeled dyedeoxy chemistry on an Applied Biosystems 377 automated sequencer (Perkin-Elmer Applied Biosystems, Foster City, CA). EF- $1 \alpha$ and mtSSU rDNA sequences have been deposited in GenBank under accession numbers AF324256-324333, or under numbers cited in O'Donnell et al. (30), Baayen et al. (4), and Geiser et al. (13). The aligned sequences are available from the second author upon request.

Phylogenetic analysis. Phylogenetic analyses of the individual and combined data sets of partial mtSSU rDNA and EF- $1 \alpha$ gene sequences were conducted using PAUP (version 4.0b3a; Sinauer Associates Inc., Sunderland, MA). Unweighted parsimony analyses were performed using the heuristic search option with 1,000 random addition sequences with mulpars on and with tree bisectionreconnection branch swapping. Sequences of $F$. beomiforme were selected for rooting the gene trees by the outgroup method based on more inclusive phylogenetic analyses $(11,28,29)$. Clade stability was assessed by 1,000 parsimony bootstrap replications. The nonparametric Wilcoxon signed-ranks (WS-R) Templeton test implemented in PAUP 4.0b3a was used to assess whether the two individual partitions could be combined. The consistency index
(CI), a measure of the amount of homoplasy in a character relative to a given cladogram, was calculated as the ratio of $m$, the minimum number of steps a character can exhibit on any cladogram, to $s$, the minimum number of steps the same character can exhibit on the cladogram in question. The retention index (RI), a measure of the amount of similarity in a character that can be interpreted as synapomorphy on a given cladogram, was calculated as the ratio of $(g-s)$ to $(g-m)$, where $g$ is the greatest number of steps a character can exhibit on any cladogram.

\section{RESULTS}

The EF- $1 \alpha$ data set consisted of 662 nucleotide characters, of which 82 were autapomorphic and 118 were cladistically informative. Maximum parsimony analysis, including autapomorphic characters, yielded 96 equally most-parsimoneous trees (MPTs) (Fig. 1) of 315 steps $(\mathrm{CI}=0.778, \mathrm{RI}=0.926)$. All of the ingroup isolates (i.e., the group under investigation in a cladistic analysis in order to resolve the relationships of its members) fell within one of two strongly supported sister clades. Of these, the basalmost clade ( $91 \%$ bootstrap) was the most phylogenetically diverse and included a $F$. nisikadoi-F. miscanthi clade (99\% bootstrap), two unnamed Fusarium spp. morphologically similar to $F$. oxysporum (one represented by isolate NRRL 25184, the other by isolates NRRL 28058 and 28387; K. O'Donnell, K. Skovgaard, and H. I. Nirenberg, unpublished data), and the G. fujikuroi complex (isolates NRRL 22016, 22057, and 22172) and F. oxysporum complex (isolates NRRL 25603, 26406, 26964, 28928, and 28973). All of the remaining ingroup isolates were represented by

TABLE 1. (Continued from preceding page)

\begin{tabular}{|c|c|c|c|c|c|}
\hline Host, substrate & Forma specialis (race) ${ }^{\mathrm{a}}$ & $\mathrm{VCG}^{\mathrm{b}}$ & Origin & $\mathrm{NRRL}^{\mathrm{c}}$ & Original code $\mathrm{e}^{\mathrm{d}}$ \\
\hline \multicolumn{6}{|l|}{ Fusarium proliferatum } \\
\hline$\ldots$ & $\ldots$ & $\ldots$ & $\ldots$ & 22057 & JFL 4853 \\
\hline \multicolumn{6}{|l|}{ Fusarium redolens } \\
\hline Asparagus officinalis & f. sp. asparagi & 0011 & The Netherlands & 28409 & CWB 1 \\
\hline Asparagus officinalis & f. sp. asparagi & 0012 & The Netherlands & 28390 & CWB 33 \\
\hline Asparagus officinalis & f. sp. asparagi & 0013 & The Netherlands & 28412 & CWB 42 \\
\hline Asparagus officinalis & f. sp. asparagi & $001-$ & The Netherlands & 28975 & IPO 97-13 \\
\hline Asparagus officinalis & f. sp. asparagi & $001-$ & The Netherlands & 28909 & IPO 97-143 \\
\hline Asparagus officinalis & f. sp. asparagi & $001-$ & The Netherlands & 28381 & IPO 97-158 \\
\hline Asparagus officinalis & f. sp. asparagi & $001-$ & Germany & 28444 & DSM 62380 \\
\hline Asparagus officinalis & f. sp. asparagi & $001-$ & Poland & 28417 & KFL63 \\
\hline Convallaria majalis & $\ldots$ & $\ldots$ & Germany & 28420 & DSM 62385 \\
\hline Dianthus barbatus & f. sp. dianthi (1) & $0001^{\mathrm{h}}$ & Germany & 28421 & DSM 62393 \\
\hline Dianthus barbatus & f. sp. dianthi (1) & 0001 & The Netherlands & 26967 & PD 89/1825 \\
\hline Dianthus barbatus & f. sp. dianthi (2) & $0002^{\mathrm{h}}$ & The Netherlands & 26966 & PD 90/1882 \\
\hline Dianthus caryophyllus & f. sp. dianthi (3) & $0003^{\mathrm{h}}$ & Italy & 26969 & 621 \\
\hline Dianthus caryophyllus & f. sp. dianthi (3) & 0003 & Italy & 28425 & 622 \\
\hline Dianthus caryophyllus & f. sp. dianthi (4) & $0004^{\mathrm{h}}$ & Germany & 25600 & DSM 62390 \\
\hline Dianthus caryophyllus & f. sp. dianthi (4) & 0004 & Germany & 28419 & DSM 62392 \\
\hline Dianthus caryophyllus & $\ldots$ & $=28355^{\mathrm{i}}$ & Germany & 28411 & DSM 62378 \\
\hline Dianthus caryophyllus & $\ldots$ & $=28411^{\mathrm{i}}$ & Germany & 28355 & DSM 62379 \\
\hline Fritillaria sp. & $\ldots$ & $\ldots$ & Germany & 28423 & DSM 62386 \\
\hline Hebe buxifolia & $\ldots$ & $\ldots$ & United States & 26440 & IMI 141126 \\
\hline Helleborus sp. & $\ldots$ & $\ldots$ & Germany & 28422 & DSM 62383 \\
\hline Hordeum vulgare & $\ldots$ & $\ldots$ & Finland & 28246 & BBA 70530 \\
\hline Linum usitatissimum & $\ldots$ & $\ldots$ & France & 28927 & F60 \\
\hline Linum usitatissimum & $\ldots$ & $\ldots$ & France & 26425 & CBS 530.96 \\
\hline Linum usitatissimum & $\ldots$ & $\ldots$ & Italy & 26762 & FO25 \\
\hline Pisum sativum & $\ldots$ & $\ldots$ & Germany & 28424 & DSM 64613 \\
\hline Pseudotsuga menziesii & $\ldots$ & $\ldots$ & Canada & 22901 & BCRI F30 \\
\hline Zea mays & $\ldots$ & $\ldots$ & Austria & 28181 & MA 1209 \\
\hline Soil & $\ldots$ & $\ldots$ & France & 26623 & 92302 \\
\hline \multicolumn{6}{|l|}{ Fusarium subglutinans } \\
\hline Zea mays & $\ldots$ & $\ldots$ & United States & 22016 & JFL 2192 \\
\hline \multicolumn{6}{|l|}{ Fusarium sp. } \\
\hline Dianthus caryophyllus & $\ldots$ & $\ldots$ & The Netherlands & 28387 & PD 90/1377 \\
\hline Peat soil & $\ldots$ & $\ldots$ & Germany & 25184 & BBA 65467 \\
\hline River sediment & $\ldots$ & $\ldots$ & Japan & 28058 & FRC 01173 \\
\hline \multicolumn{6}{|l|}{ Fusarium verticillioides } \\
\hline Zea mays & $\ldots$ & $\ldots$ & Germany & 22172 & BBA 11778 \\
\hline
\end{tabular}


a strongly supported $F$. redolens $-F$. hostae clade $(100 \%$ bootstrap). Parsimony analysis of the 706-bp mtSSU rDNA partition (15 autapomorphies, 49 synapomorphies) yielded $>10,000$ equally MPTs 115 steps in length $(\mathrm{CI}=0.774, \mathrm{RI}=0.908)$ (Fig. 2$)$. The G. fujikuroi complex ( $88 \%$ bootstrap) formed a basal sister group to the remaining ingroup taxa. The remaining ingroup isolates formed a clade ( $87 \%$ bootstrap) composed of the following sister clades: (i) Fusarium spp., F. nisikadoi-F. miscanthi, and the $F$. oxysporum complex (92\% bootstrap); and (ii) $F$. hostae-F. redolens ( $73 \%$ bootstrap). A strongly supported $F$. nisikadoi-F. miscanthi clade (100\% bootstrap) was resolved as the putative sister group of the F. oxysporum complex ( $82 \%$ bootstrap). Re-

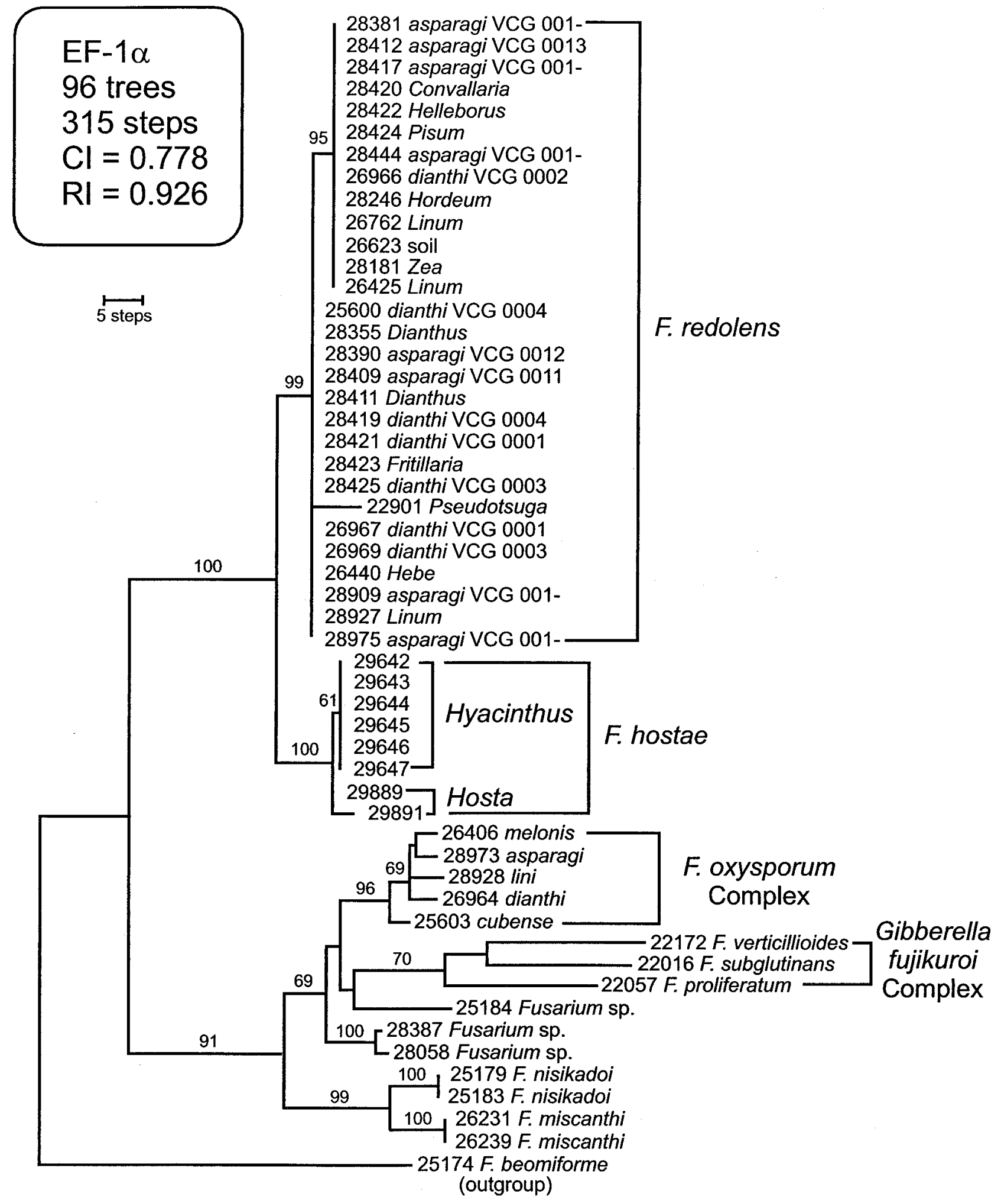

Fig. 1. One of 96 most-parsimonious phylograms inferred from the 662 aligned elongation factor $1 \alpha$ (EF-1 $\alpha$ ) nucleotide characters showing phylogenetic relationships of the Fusarium redolens $-F$. hostae clade (100\% bootstrap interval) and related species. Three closely related EF-1 $\alpha$ haplotypes were resolved within $F$. redolens. A sequence of $F$. beomiforme was used to root the tree by the outgroup method. Bootstrap values $>50 \%$ from 1,000 maximum parsimony replications implemented in PAUP (version 4.0b3a) are indicated above nodes. $\mathrm{CI}=$ consistency index and RI $=$ retention index. 
sults of the WS-R Templeton test implemented in PAUP indicated that the EF- $1 \alpha$ and mtSSU rDNA data sets could be combined $(P=$ 0.0956 constraining mtSSU rDNA data to EF- $1 \alpha 70 \%$ bootstrap consensus, and $P=0.007$ constraining EF- $1 \alpha$ data to $\mathrm{mtSSU}$ rDNA bootstrap consensus). Maximum parsimony searches on the combined data set (Fig. 3) yielded >5,000 MPTs 441 steps in length $(\mathrm{CI}=0.575, \mathrm{RI}=0.912)$. A strongly supported $F$. hostae $-F$. redolens clade (100\% bootstrap) was resolved as sister to the remaining ingroup taxa, which formed a moderately well supported clade (79\% bootstrap). A F. nisikadoi-F. miscanthi clade ( $100 \%$ bootstrap) formed a putative sister group to the $F$. oxysporum complex ( $<50 \%$ bootstrap support).
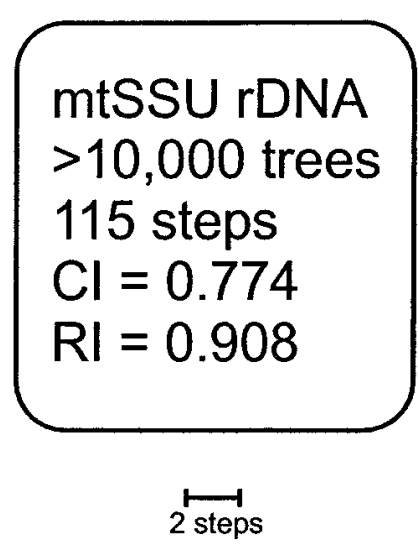

62

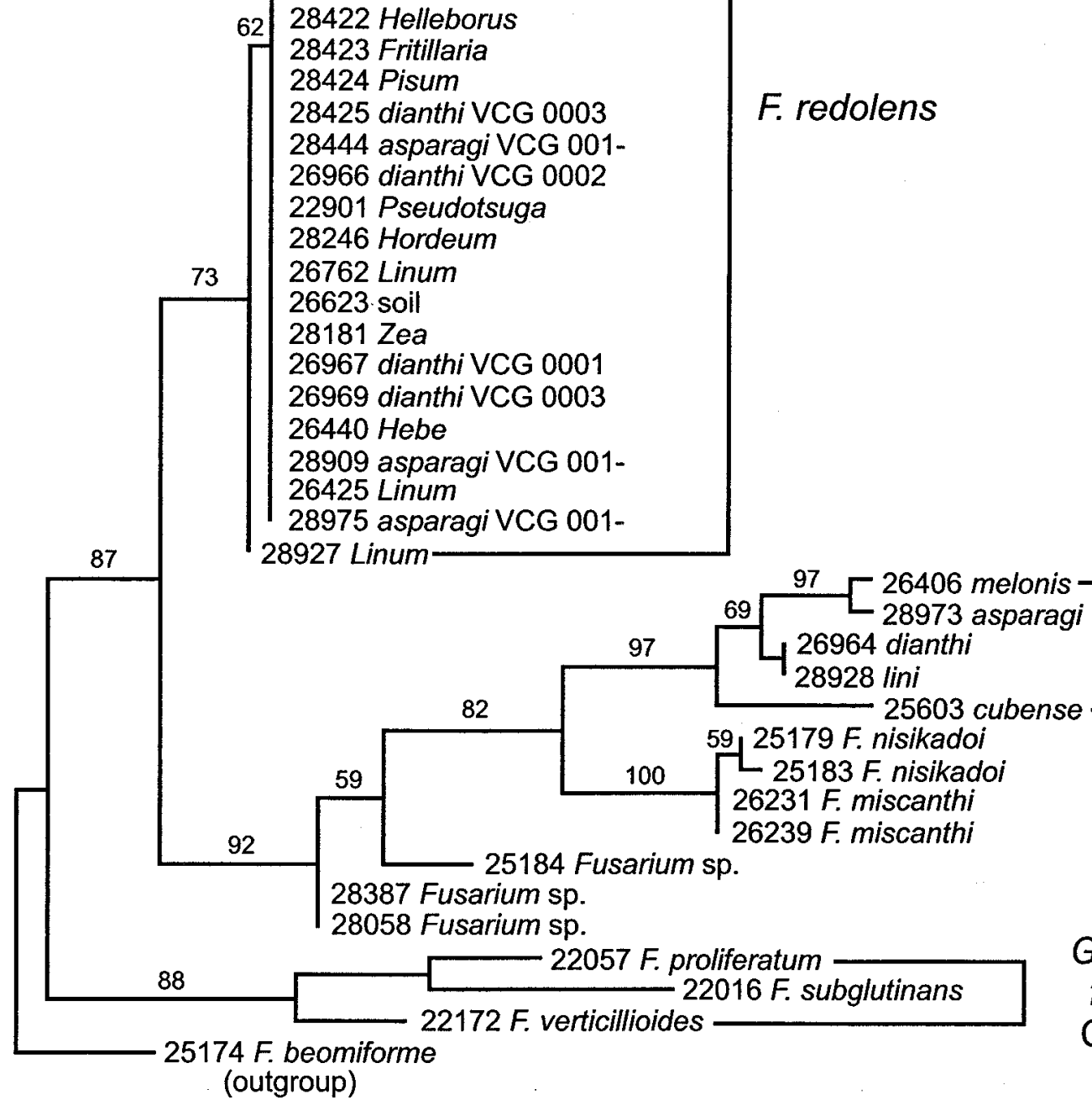

\section{F. hostae}

29642

29644

29645

29646

29647

29889

29891

25600 dianthi VCG 0004 28355 Dianthus

28381 asparagi VCG 001 -

28390 asparagi VCG 0012

28409 asparagi VCG 0011

28411 Dianthus

28412 asparagi VCG 0013

28417 asparagi VCG 001-

28419 dianthi VCG 0004

28420 Convallaria

28421 dianthi VCG 0001

28422 Helleborus

Hosta

osta

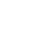

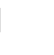

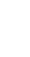


Genetic diversity within $F$. redolens was small as reflected in the discovery of only three EF-1 $\alpha$ (Fig. 1) and two mtSSU rDNA (Fig. 2) haplotypes. Isolates belonging to the same VCG always shared the same multilocus haplotype (Fig. 3). Of the 14 isolates sharing identical EF- $1 \alpha$ and mtSSU rDNA haplotypes at the root of the $F$. redolens clade (Fig. 3), four were $F$. redolens $\mathrm{f}$. sp. asparagi, six were $F$. redolens f. sp. dianthi (all members of VCGs 0001, 0003, and 0004), two represented a putatively nonpathogenic VCG from carnation, and the remaining two were from Fritillaria and Hebe spp. (the latter isolate was received as F. oxysporum f. sp. hebae). A pathogenic isolate from Linum usitatissimum (NRRL 28927) (19) differed from the basal haplo-

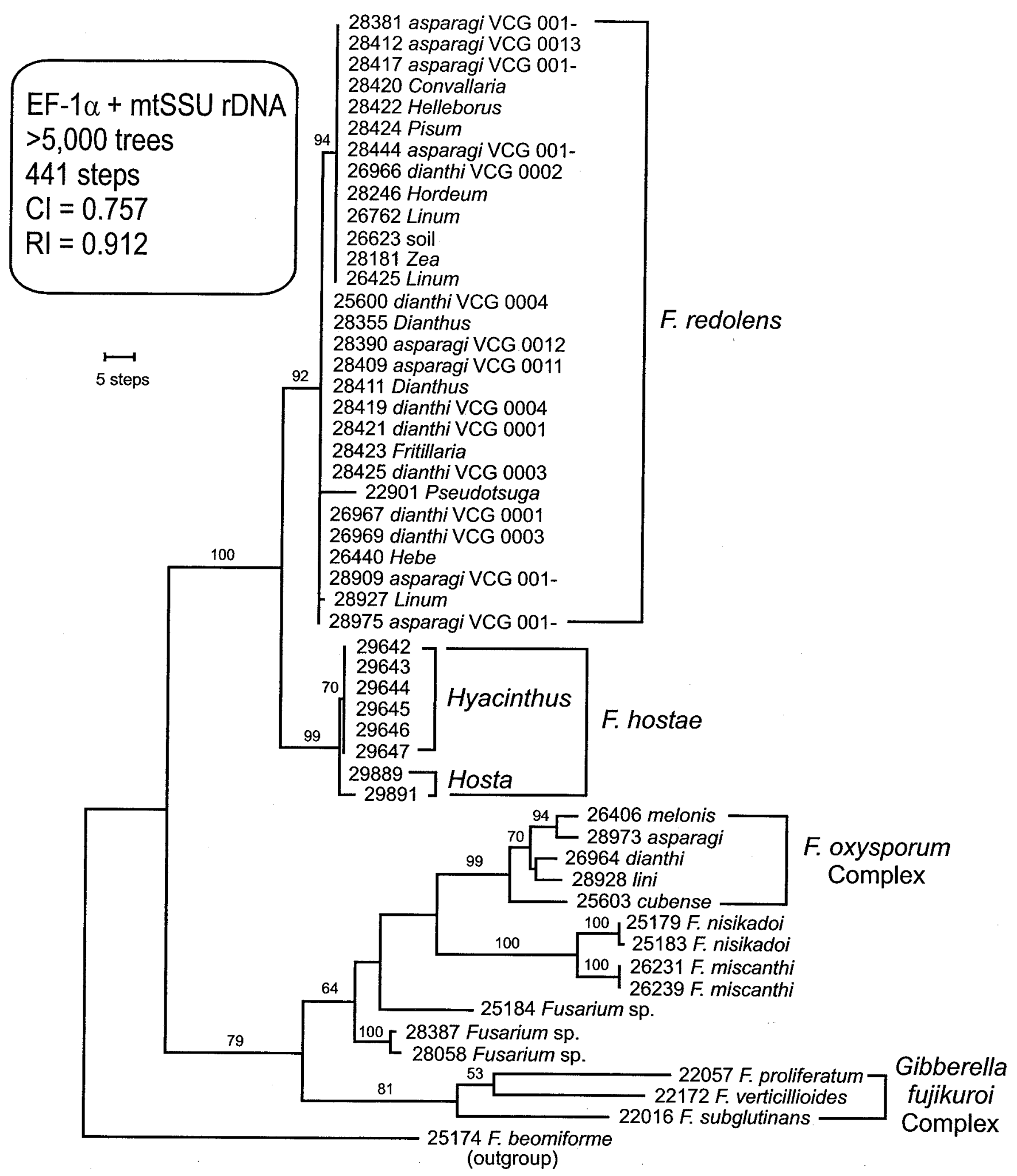

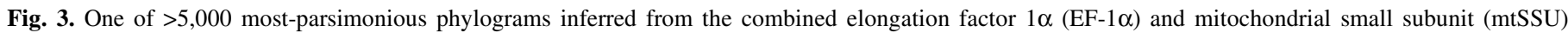
ribosomal DNA (rDNA) data set. Bootstrap intervals from 1,000 replicates are indicated above nodes. Note that the Fusarium redolens-F. hostae clade is strongly supported as monophyletic (100\% bootstrap). Except for two isolates that possess unique haplotypes, $F$. redolens isolates are nearly evenly divided among two closely related multilocus haplotypes. Note that isolates pathogenic to Asparagus (f. sp. asparagi), Dianthus (f. sp. dianthi), and Linum spp. are nested within each of the two major subclades within $F$. redolens. $\mathrm{CI}=$ consistency index and $\mathrm{RI}=$ retention index. 
type by a single substitution. Thirteen $F$. redolens isolates, representing a third EF- $1 \alpha$ and mtSSU rDNA haplotype, formed a clade (Fig. 3; 94\% bootstrap) composed of the following: two isolates from L. usitatissimum (NRRL 26425 and 26762), one isolate of VCG 0002 of $F$. redolens f. sp. dianthi (NRRL 26966), four isolates of $F$. redolens $\mathrm{f}$. sp. asparagi together with isolates from Convallaria, Helleborus, Pisum, Hordeum, and Zea spp., and one isolate from soil. A fourth haplotype which differed by seven substitutions from the basal haplotype was represented by a single isolate (NRRL 22901) from Pseudotsuga menziesii.

Results of the molecular phylogeny indicate that the six isolates from hyacinth collected in The Netherlands as $F$. oxysporum $\mathrm{f}$. sp. hyacinthi, and suspected by us to belong to $F$. redolens, are $F$. hostae. The six $F$. hostae isolates from hyacinth represent a random subset of a larger collection isolated from various cultivars of this host in The Netherlands. In a preliminary study, restriction digest patterns of the ITS region of the rDNA had classified these isolates as distinct from $F$. oxysporum; the ITS-restriction fragment length polymorphisms were identical to that of $F$. redolens and a number of species in the G. fujikuroi complex. Morphological reexamination of these isolates, however, revealed that they produce thick macroconidia as well as polyphialides, confirming their identification as $F$. hostae rather than $F$. oxysporum or $F$. redolens.

\section{DISCUSSION}

In the present study, partial EF- $1 \alpha$ gene and mtSSU rDNA nucleotide sequences were used to infer phylogenetic relationships within and among a newly discovered lineage, the $F$. redolens $-F$. hostae clade (13), and other Gibberella fusaria. The merits and power of multiple gene phylogenies for resolving species phylogenies have been shown in a recent review on phylogenetic species recognition and species concepts in fungi (37). In various lineages of the genus Fusarium, the consistent concordance of several nuclear and mitochondrial genealogies indeed offers compelling evidence that the gene trees reflect the underlying phylogenies $(4,27-32)$. Each of the G. fujikuroi and Nectria haematococca species complexes, once considered by Snyder and Hansen (35) to be represented by $F$. moniliforme and $F$. solani, respectively, are now known to harbor over 40 phylogenetically distinct species with a hypothesized Gondwanic biogeographical history $(27,29,32)$. All of the mating populations (biological species) in each of these two complexes were resolved as exclusive groups using molecular phylogenetics. Moreover, the multigene phylogeny approach facilitated the discovery of species-defining morphological characters within the G. fujikuroi complex, thus characterizing hitherto unknown morphological species $(25,26)$. Recently, $F$. graminearum (teleomorph: G. zeae), the causal agent of wheat scab, was found to consist of seven biogeographically structured lineages that appear to represent phylogenetically distinct species, among which gene flow has been very limited during their more recent evolutionary history (31). The multigene approach used in the latter study also allowed for the identification of a hybrid isolate between two of the lineages. In all, 15 heterothallic, 7 homothallic, and 4 putatively mitosporic species were identified in the $N$. haematococca species complex (27). In the F. oxysporum complex, amplified fragment length polymorphism-based genealogies have been shown to support the multigene phylogenies, resolving numerous evolutionarily distinct clonal lineages $(4,30)$.

As first reported by Gams et al. (11), the F. oxysporum complex and the $F$. miscanthi-F. nisikadoi clade, together with two unnamed $F$. oxysporum-like species (one represented in the present study by isolate NRRL 25184, the other by isolates NRRL 28058 and 28387) and the G. fujikuroi complex, form a monophyletic group independent from $F$. redolens. Our results confirm those of Geiser et al. (13) that $F$. redolens and $F$. hostae form a separate monophyletic lineage. As estimated from EF- $1 \alpha$ and $\mathrm{mtSSU}$
rDNA partial sequences, genetic diversity in the $F$. redolens $-F$. hostae clade was low compared to any of the three major clades in the $F$. oxysporum complex $(4,30)$. Within $F$. redolens, no more than three EF- $1 \alpha$ and two mtSSU rDNA haplotypes were found, and three EF- $1 \alpha$ and a single mtSSU rDNA haplotype in $F$. hostae. Remarkably, all isolates of the latter species from hyacinths shared a unique EF-1 $\alpha$ haplotype different from those described from isolates from Hosta spp. (13).

Pathogenic diversity in $F$. redolens resembles that in $F$. oxysporum in that isolates of $F$. redolens have been associated with a wide range of diseases, including wilts, seedling damping-off, and cortical rot $(10,14,15)$. Although isolates within the $F$. oxysporum complex sharing host specificity have been grouped traditionally in formae speciales, only three formae speciales have been described within F. redolens: F. redolens f. sp. dianthi Gerlach (15), $F$. redolens f. sp. spinaciae (Sherb.) Subramanian (36), and $F$. redolens $\mathrm{f}$. sp. asparagi Baayen (5). It is reasonable to assume, however, that tests for host specificity may reveal that more pathogenic forms exist within this species. For example, isolate NRRL 28927 from Linum spp. causes typical root rot symptoms similar to those induced by $F$. oxysporum $\mathrm{f}$. sp. lini (this is isolate F60 in Kroes et al. [19]), and it is noteworthy that the original description of $F$. redolens was based on isolates pathogenic to Pisum sativum causing disease symptoms similar to those induced by F. oxysporum f. sp. pisi. Further, because isolate NRRL 26440 from Hebe buxifolia was received as $F$. oxysporum f. sp. hebae Raabe $(12,33,34)$, additional isolates from Hebe spp. should be investigated to determine whether other (or all) members of this forma specialis belong to $F$. redolens.

Host preference in $F$. redolens did not correlate with the two major subclades resolved within this species by the molecular phylogeny. Three VCGs of $F$. redolens f. sp. dianthi and one putatively nonpathogenic VCG from a Dianthus sp. had the same genotype, but a fourth VCG, 0002, was phylogenetically distinct. The same was the case for $F$. redolens $\mathrm{f}$. sp. asparagi, in which both genotypes were nearly evenly divided among each of the two major subclades within $F$. redolens. Isolates from flax had distinct genotypes as well. Collectively, these results suggest that members of these $F$. redolens formae speciales may have independent evolutionary origins. Within the $F$. oxysporum complex, the majority of formae speciales with two or more VCGs appear to be either para- or polyphyletic as well $(4,30)$. In contrast, formae speciales in the G. fujikuroi complex and $N$. haematococca species complex all appear to be monophyletic, except for two polyphyletic cucurbit pathogens within the $N$. haematococca species complex (27), but this is not surprising because so-called formae speciales within these two latter species complexes actually represent phylogenetically and biologically distinct species $(22,25,27,29,32)$.

Although isolates of $F$. redolens f. sp. spinaciae (Sherb.) Subramanian were not available for study, Sherbakoff's original description and illustrations of the type isolate of $F$. spinaciae (18) beyond any doubt identify this fungus as $F$. redolens as well. Consequently, Snyder and Hansen (35) were mistaken in placing this fungus in $F$. oxysporum, as $F$. oxysporum Schlechtend.:Fr. f. sp. spinaciae (Sherb.) W. C. Snyder \& H. N. Hans. To further complicate the matter, molecular studies have shown that $F$. oxysporum also harbors three VCGs (VCG 0330-0332), of which the isolates are pathogenic to spinach (4). These isolates are in lack of a valid name, because the type used by Snyder and Hansen (35) to define f. sp. spinaciae belonged to an entirely different species. We therefore propose a new combination, $F$. oxysporum Schlechtend.:Fr. f. sp. spinaciae Baayen, for isolates of $F$. oxysporum with pathogenicity to spinach such as those in VCG 0330-0332.

Results of the present study demonstrate that six isolates previously identified as $F$. oxysporum f. sp. hyacinthi (9) belong to $F$. hostae. Prior to the present study, the latter species has only been 
reported from container-grown Hosta spp. in South Carolina $(13,40)$. However, preliminary results suggest that this species is widespread on hyacinths in The Netherlands, where it is associated with various disease symptoms, including bulb rot, root rot, cracking of the basal plate, and skin damage without any rot development $(2,9,23)$. Presently it is unknown whether any pathogenic isolates from hyacinth belong to $F$. oxysporum: all 14 isolates at the Bulb Research Center, Lisse, The Netherlands, proved to belong to F. hostae (M. de Boer and S. Breeuwsma, unpublished data). Pathogenicity tests are being conducted to determine whether isolates of F. hostae from Hosta and Hyacinthus spp. are pathogenic to both hosts.

\section{ACKNOWLEDGMENTS}

Names are necessary to report factually on available data; however, the USDA neither guarantees nor warrants the standard of the product, and the use of the name by USDA implies no approval of the product to the exclusion of others that may also be suitable. We thank S. Prather for preparing the publication figures.

\section{LITERATURE CITED}

1. Aloi, C., and Baayen, R. P. 1993. Examination of the relationships between vegetative compatibility groups and races in Fusarium oxysporum f. sp. dianthi. Plant Pathol. 42:839-850.

2. Anonymous. 1983. Pages 44-46 in: Ziekten in bolgewassen 1 (ed. 2). Laboratorium voor Bloembollenonderzoek, Lisse, The Netherlands.

3. Baayen, R. P., and Gams, W. 1988. The Elegans fusaria causing wilt disease of carnation. I. Taxonomy. Neth. J. Plant Pathol. 94:273-288.

4. Baayen, R. P., O'Donnell, K., Bonants, P. J. M., Cigelnik, E., Kroon, L. P. N. M., Roebroeck, E. J. A., and Waalwijk, C. 2000. Gene genealogies and AFLP analyses within the Fusarium oxysporum complex identify monophyletic and non-monophyletic formae speciales causing wilt and rot disease. Phytopathology 90:891-900.

5. Baayen, R. P., Van den Boogert, P. H. J. F., Bonants, P. J. M., Poll, J. T. K., Blok, W. J., and Waalwijk, C. 2000. Fusarium redolens f. sp. asparagi, causal agent of asparagus root rot, crown rot and spear rot. Eur. J. Plant Pathol. 106:907-912.

6. Baayen, R. P., Van Dreven, F., Krijger, M. C., and Waalwijk, C. 1997. Genetic diversity in Fusarium oxysporum f. sp. dianthi and Fusarium redolens f. sp. dianthi. Eur. J. Plant Pathol. 103:395-408.

7. Bilai, V. I. 1955. Fusarii. Izd Akad Nauk Ukrain SSR, Kiev, USSR.

8. Blok, W. J., and Bollen, G. J. 1997. Host specificity and vegetative compatibility of Dutch isolates of Fusarium oxysporum f. sp. asparagi. Can. J. Bot. 75:383-393.

9. Boerema, G. H., and Hamers, M. E. C. 1988. Check-list for scientific names of common parasitic fungi. Series 3a: Fungi on bulbs: Liliaceae. Neth. J. Plant Pathol. 94(Suppl.)1:1-32.

10. Booth, C. 1971. The genus Fusarium. Commonwealth Mycological Institute, Kew, U.K.

11. Gams, W., Klamer, M., and O'Donnell, K. 1999. Fusarium miscanthi sp. nov. from Miscanthus litter. Mycologia 91:263-268.

12. Garibaldi, A., Minuto, A., Gilardi, G., and Gullino, M. L. 2000. First report of Fusarium wilt on Hebe sp. in Italy and Europe. Plant Dis. 84:705.

13. Geiser, D. M., Juba, J. H., Wang, B., and Jeffers, S. N. Fusarium hostae sp. nov., a relative of $F$. redolens with a Gibberella teleomorph. Mycologia. (In press.)

14. Gerlach, W. 1961. Fusarium redolens Wr., seine Morphologie und systematische Stellung. Ein Beitrag zur Kenntnis der Elegans-Fusarien. Phytopathol. Z. 42:150-160.

15. Gerlach, W., and Pag, H. 1961. Fusarium redolens Wr., seine phytopathologische Bedeutung und eine an Dianthus-Arten gefäßparasitäre Form (F. redolens Wr. f. dianthi Gerlach). Phytopathol. Z. 42:349-361.

16. Gordon, W. L. 1952. The occurrence of Fusarium species in Canada. II. Prevalence and taxonomy of Fusarium species in cereal seed. Can. J. Bot. 30:236-238.

17. Ho, Y. W., Varghese, G., and Taylor, G. S. 1985. Fusarium oxysporum var. redolens from Africa as a cause of vascular wilt disease of oil palm. Phytopathol. Z. 113:373-376.

18. Hungerford, C. W. 1923. Fusarium wilt of spinach. Phytopathology
13:205-209.

19. Kroes, G. M. L. W., Löffler, H. J. M., Parlevliet, J. E., Keizer, L. C. P., and Lange, W. 1999. Interactions of Fusarium oxysporum f. sp. lini, the flax wilt pathogen, with flax and linseed. Plant Pathol. 48:491-498.

20. Larsson, M., and Olofsson, J. 1994. Prevalence and pathogenicity of spinach root pathogens of the genera Aphanomyces, Phytophthora, Fusarium, Cylindrocarpon, and Rhizoctonia in Sweden. Plant Pathol. 43:251-260.

21. Manicom, B. Q., and Baayen, R. P. 1993. Restriction fragment length polymorphisms in Fusarium oxysporum f. sp. dianthi and other fusaria from Dianthus species. Plant Pathol. 42:851-857.

22. Matuo, T., and Snyder, W. C. 1973. Use of morphology and mating populations in the identification of formae speciales in Fusarium solani. Phytopathology 63:562-565.

23. Muller, P. J. 1978. Krasbodems, vethuidigheid en bolrot bij hyacinten. Weekblad voor Bloembollencultuur 89(16):389-391.

24. Nelson, P. E., Toussoun, T. A., and Marasas, W. F. O. 1983. Fusarium species. An Illustrated Manual for Identification. Pennsylvania State University Press, University Park.

25. Nirenberg, H. I., and O'Donnell, K. 1998. New Fusarium species and combinations within the Gibberella fujikuroi species complex. Mycologia 90:434-458

26. Nirenberg, H. I., O’Donnell, K., Kroschel, J., Andrianaivo, A. P., Frank, J. M., and Mubatanhema, W. 1998. Two new species of Fusarium: Fusarium brevicatenulatum from the noxious weed Striga asiatica in Madagascar and Fusarium pseudoanthophilum from Zea mays in Zimbabwe. Mycologia 90:459-464.

27. O'Donnell, K. 2000. Molecular phylogeny of the Nectria haematococca-Fusarium solani species complex. Mycologia 92:919-938.

28. O'Donnell, K., and Cigelnik, E. 1997. Two divergent intragenomic rDNA ITS2 types within a monophyletic lineage of the fungus Fusarium are nonorthologous. Mol. Phylogenet. Evol. 7:103-116.

29. O'Donnell, K., Cigelnik, E., and Nirenberg, H. I. 1998. Molecular systematics and phylogeography of the Gibberella fujikuroi species complex. Mycologia 90:465-493.

30. O’Donnell, K., Kistler, H. C., Cigelnik, E., and Ploetz, R. 1998. Multiple evolutionary origins of the fungus causing Panama disease of banana: Concordant evidence from nuclear and mitochondrial gene genealogies. Proc. Natl. Acad. Sci. USA 95:2044-2049.

31. O'Donnell, K., Kistler, H. C., Tacke, B. K., and Casper, H. H. 2000. Gene genealogies reveal global phylogeographic structure and reproductive isolation among lineages of Fusarium graminearum, the fungus causing wheat scab. Proc. Natl. Acad. Sci. USA 97:7905-7910.

32. O'Donnell, K., Nirenberg, H. I., Aoki, T., and Cigelnik, E. 2000. A multigene phylogeny of the Gibberella fujikuroi species complex: Detection of additional phylogenetically distinct species. Mycoscience 41:61-78.

33. Raabe, R. D. 1957. Fusarium wilt of Hebe buxifolia. (Abstr.) Phytopathology 47:532.

34. Raabe, R. D. 1985. Fusarium wilt of Hebe species. Plant Dis. 69:450451.

35. Snyder, W. C., and Hansen, H. N. 1940. The species concept in Fusarium. Am. J. Bot. 27:64-67.

36. Subramanian, C. V. 1971. Hyphomycetes. An Account of Indian Species, Except Cercosporae. Indian Council for Agricultural Research, New Delhi, India.

37. Taylor, J. W., Jacobson, D. J., Kroken, S., Kasuga, T., Geiser, D. M., Hibbett, D. S., and Fisher, M. C. 2001. Phylogenetic species recognition and species concepts in fungi. Fungal Genet. Biol. 21:21-32.

38. Waalwijk, C., Baayen, R. P., De Koning, J. R. A., and Gams, W. 1996. Ribosomal DNA analyses challenge the status of Fusarium sections Liseola and Elegans. Sydowia Ann. Mycol. 48:90-104.

39. Waalwijk, C., De Koning, J. R. A., Baayen, R. P., and Gams, W. 1996. Discordant groupings of Fusarium spp. from sections Elegans, Liseola and Dlaminia based on ribosomal ITS1 and ITS2 sequences. Mycologia 88:361-368.

40. Wang, B., and Jeffers, S. N. 2000. Fusarium root and crown rot: A disease of container-grown hostas. Plant Dis. 84:980-988.

41. White, T. J., Bruns, T., Lee, S., and Taylor, J. 1990. Amplification and direct sequencing of fungal ribosomal RNA genes for phylogenetics. Pages 315-322 in: PCR Protocols: A Guide to Methods and Applications. M. A. Innes, D. H. Gelfand, J. J. Sninsky, and T. J. White, eds. Academic Press, San Diego, CA.

42. Wollenweber, H. W. 1913. Studies on the Fusarium problem. Phytopathology $3: 24-50$

43. Wollenweber, H. W. 1916-1935. Fusaria Autographice Delineata. Berlin. 